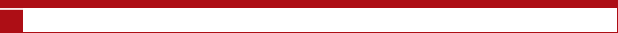

SECCIÓN: Informes y avances de investigación
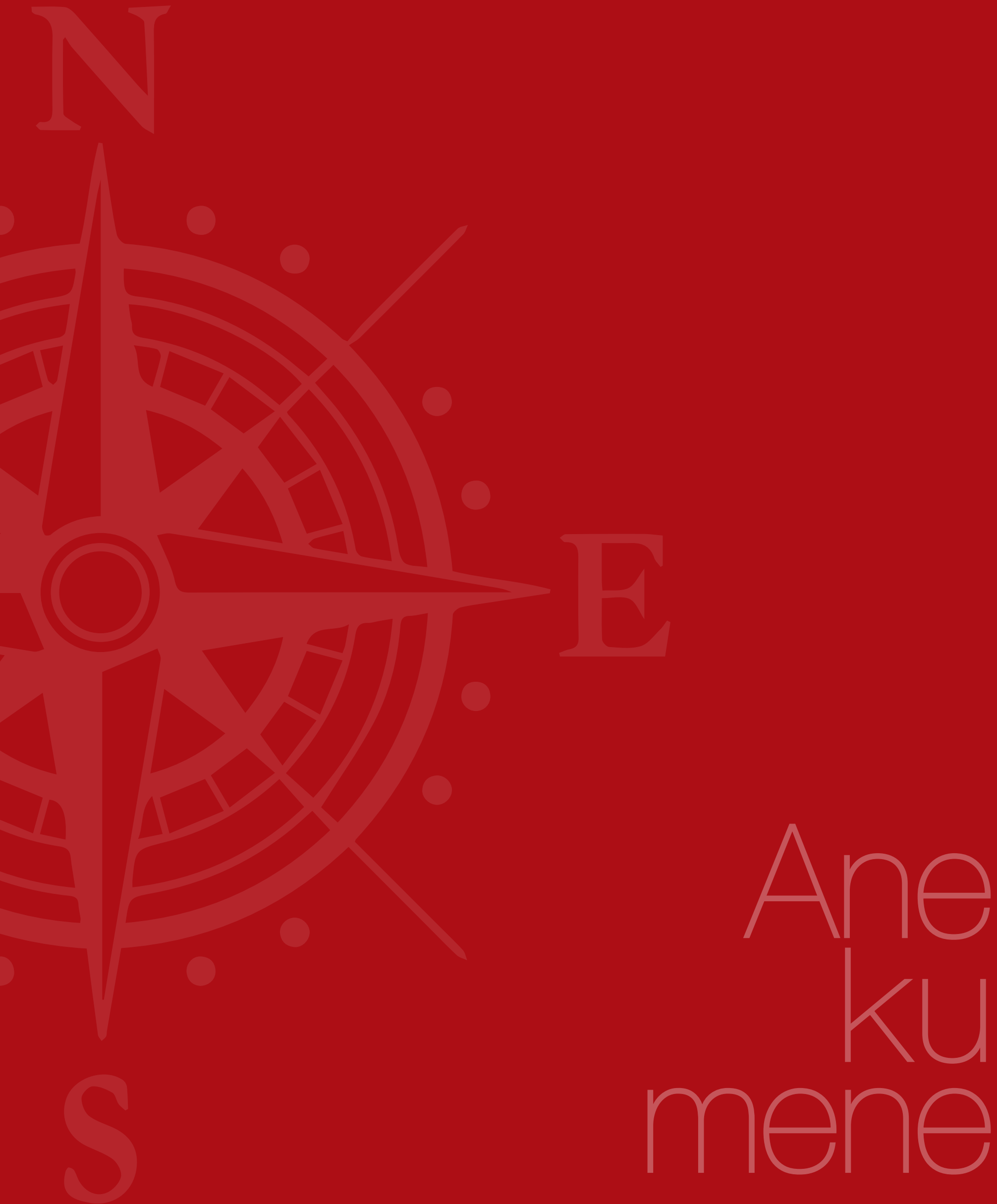


\section{A pesquisa-ação como metodologia na construção do Atlas Escolar Geográfico Municipal de Conceição de Macabu/RJ}

La investigación-acción como metodología en la construcción del Atlas Escolar Geográfico Municipal de Conceição de Macabu/RJ

The Action Research as a Methodology in the Construction of the Municipal Geographic School Atlas of Conceição de Macabu/RJ

Renato Batista da Conceição*

Esther Kuperman**

\section{Resumo}

O presente trabalho é responsável por uma pesquisa de mestrado na fase de conclusão sobre a produção de um atlas escolar geográfico municipal aplicado à Educação Básica. $\mathrm{O}$ artigo tem como referencial teórico-metodológico os orçamentos da pesquisa-ação, que tem como uma de suas características fundamentais a realização de investigações colaborativas que favoreçam a participação criativa e construtiva dos sujeitos envolvidos.

\section{Palavras-chave}

Pesquisa-ação; atlas escolar; cartografia escolar.

* Colégio Pedro II.

** Colégio Pedro II. 
A pesquisa-ação como metodologia na construção do Atlas Escolar

Geográfico Municipal de Conceição de Macabu/RJ

Renato Batista da Conceição / Esther Kuperman /

\section{Resumen}

El presente trabajo da cuenta de una investigación de maestría en fase de conclusión sobre la producción de un atlas escolar geográfico municipal aplicado a la Educación Básica. El artículo tiene como referente teórico-metodológico los presupuestos de la investigación-acción, una de cuyas características fundamentales es la realización de investigaciones colaborativas que propician la participación creadora y constructiva de los sujetos involucrados.

\section{Abstract}

This paper accounts for a master's research in the conclusion phase about the production of a municipal geographic school atlas applied to Basic Education. The article has as a theoretical-methodological reference the assumptions of action-research, which has as one of its fundamental characteristics the development of collaborative investigations that foster the creative and constructive participation of the subjects involved.

\section{Palabras clave}

Investigación-acción; atlas escolar; cartografía escolar.

\section{Keywords}

Action research; school atlas; school cartography. 


\section{Introdução}

O presente trabalho está relacionado à linha de pesquisa do Programa de Mestrado Profissional em Práticas de Educação Básica do Colégio Pedro II, intitulada "Linguagens e letramento no Ensino Básico" e ao grupo de pesquisa de Produção de Materiais Didáticos em Humanidades da mesma instituição. $O$ problema central de pesquisa parte de experiências oriundas do ensino de Geografia na Educação Básica, especificamente do pesquisador em sua atuação na Rede Municipal de Educação de Conceição de Macabu, município localizado no interior do estado do Rio de Janeiro, na região Norte Fluminense.

Desde o início da atuação do professor-pesquisador na rede municipal de educação anteriormente citada, observou-se um grande problema de carência de materiais didáticos relacionados à geografia local do município, e consequentemente, uma grande dificuldade dos professores de Geografia do Ensino Fundamental em trabalharem com a temática em sala de aula.

Diante do problema encontrado no local de atuação profissional como professor de Geografia, algumas questões iniciaram e continuam sendo norteadoras da presente pesquisa: É possível a construção de materiais didáticos pelos próprios professores de Geografia inseridos no contexto da Educação? De que forma o uso de um atlas escolar geográfico municipal pode contribuir, como um material didático, no processo de alfabetização e letramento cartográfico dos alunos no Ensino Fundamental? Quais os limites, possibilidades e desafios no processo de planejamento, elaboração e avaliação de um atlas escolar geográfico municipal construído por e para o trabalho de professores de Geografia com alunos da Educação Básica?

Segundo levantamento realizado através da análise dos grupos de pesquisas e eventos acadêmicos ligados à cartografia escolar no Brasil, verificou-se que os atlas escolares geográficos municipais no país são em geral elaborados por cartógrafos ou geógrafos presentes em laboratórios de grupos de pesquisas nas universidades ou em empresas ligadas a cartografia. Por exemplo, no estado do Rio de Janeiro, alguns municípios já possuem atlas escolares municipais disponíveis nas escolas por meio da parceria entre as universidades e/ou empresas privadas e as prefeituras, como por exemplo nos municípios do Rio de Janeiro, Itaboraí, Rio Bonito, Nova Friburgo, Nova Iguaçu, Duque de Caxias, Macaé e Quissamã.

Ressalta-se aqui as complexidades relacionadas aos atlas escolares geográficos municipais elaborados sem a efetiva participação dos indivíduos (professores da Educação Básica) ligados diretamente ao processo de ensino-aprendizagem, visto que correm o risco, por diversos motivos, de ficarem esquecidos nas prateleiras das bibliotecas das escolas e não contribuírem na melhoria da aprendizagem dos alunos com relação à utilização da cartografia escolar no ensino de Geografia.

\section{Justificativa}

Na última década, as recomendações curriculares oficiais da disciplina de Geografia para o Ensino Fundamental estão incentivado a produção de atlas escolares geográficos municipais, uma vez que permitem incluir num só material didático, mapas, textos, fotografias, gráficos e atividades a respeito da cartografia local. Esse trabalho possui uma relevância social, pois beneficiará não somente os alunos e professores do município de Conceição de Macabu, mas também, as demais pessoas interessadas em estudar a geografia do município de Conceição de Macabu através de mapas e dados atualizados.

Ressalta-se também a compreensão de que a pesquisa está contribuindo com o aprimoramento da prática pedagógica do professor-pesquisador, e também, a prática de outros professores de Geografia do município que estão contribuindo no processo de planejamento, produção e avaliação do Atlas Escolar Geográfico Municipal.

É preciso ressaltar que a cartografia escolar hegemonicamente ensinada, pode servir para alienar os alunos ou abrir suas mentes para a compreensão crítica do espaço em que vivem. Trata-se de uma opção dos professores, que muitas vezes, escolhem não dialogar com a realidade dos estudantes, não os inculcando formas de compreensão do mundo sensível, que leve-os ao exercício de um saber posicional em diferentes escalas geográficas, ou seja, reflexões de fenômenos geográficos do local ao global.

\section{Objetivos gerais e específicos}

De acordo com o problema delimitado anteriormente, o objetivo geral da pesquisa é refletir sobre o processo metodológico de construção de um atlas escolar geográfico municipal para alunos do Ensino Fundamental (Anos Finais) através da metodologia da pesquisa-ação e na perspectiva da alfabetização e letramento cartográfico com a participação de professores de Geografia ligados diretamente a Educação Básica. Já como objetivos específicos, os seguintes:

- Confeccionar o atlas escolar geográfico municipal no espaço e cotidiano da escola pública.

- Avaliar as potencialidades e lacunas do atlas escolar geográfico municipal elaborado para as aulas de Geografia nos Anos Finais do Ensino Fundamental.

- Disponibilizar o material didático para o uso dos professores de Geografia da Rede Municipal de Educação de Conceição de Macabu. 


\section{Materiais e métodos}

A presente pesquisa possui uma abordagem qualitativa e utiliza o próprio espaço escolar da educação básica para coleta de dados, interpretação de fenômenos e atribuição de significados. Ressalta-se que existe uma vasta gama de razões que determinam a realização de uma pesquisa qualitativa. Segundo Gil (2010), as razões podem ser classificadas em dois grandes grupos: razões de ordem intelectual e razões de ordem prática. As de ordem intelectual estão relacionadas ao "desejo de conhecer pela própria satisfação de conhecer” (Gil, 2010, p. 1). Já as de ordem prática estão relacionadas ao "desejo de conhecer com vistas a fazer algo de maneira mais eficiente ou eficaz" (Gil, 2010, p. 1).

Quanto aos procedimentos metodológicos, optou-se por utilizar os procedimentos do tipo de pesquisa-ação. De acordo com Gil (2010), "é uma modalidade de pesquisa que não se ajusta ao modelo clássico de pesquisa, cujo propósito é o de proporcionar a aquisição de conhecimentos claros, precisos e objetivos" (p. 42). A pesquisa-ação é compreendida como "um tipo de pesquisa com base empírica que é concebida e realizada em estreita associação comum a ação ou ainda com a resolução de um problema coletivo, onde todos os pesquisadores e participantes estão envolvidos de modo cooperativo e participativo" (Thiollent, 2011, p. 20). David Tripp (2005) apresenta quatro fases do ciclo básico desse tipo de pesquisa:

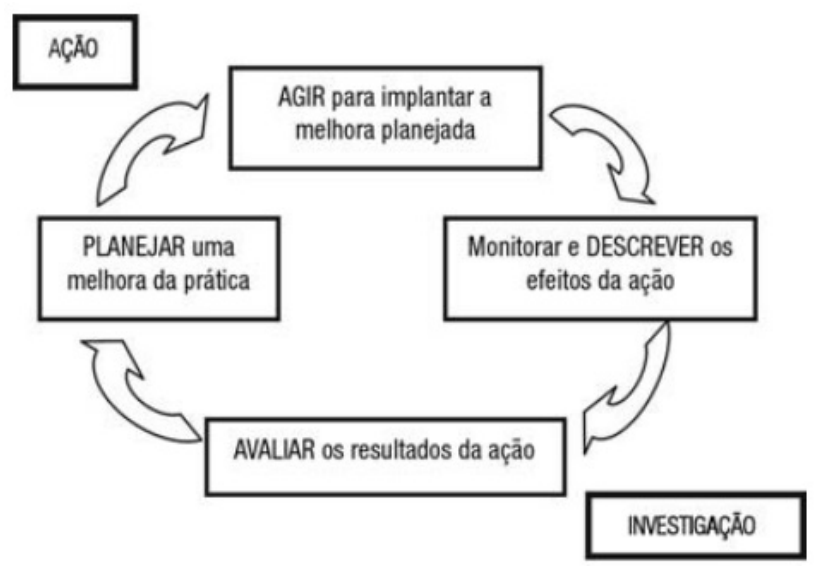

Figura 1. Fases do ciclo básico da investigação-ação Fonte: Tripp (2005).

É percebido através do esquema apresentando que há um contínuo no processo de pesquisa, que se inicia com o estabelecimento de um problema, o planejamento e aplicação de uma ação e prossegue com a avaliação e o replanejamento de acordo com a nova situação apresentada. Em outras palavras, há uma reflexão contínua que se desenrola a cada aplicação e reavaliação das ações buscando sempre a melhora da prática.
Vale destacar que o problema a ser trabalhado não é definido somente pelo olhar do pesquisador, mas também, e principalmente, pelos sujeitos e pelas práticas destes, observadas no ambiente em que vivem, trabaIham e se relacionam e, ainda, a ação a ser implementada é planejada em parceria com os participantes da pesquisa (pesquisador e sujeitos).

Esse tipo de pesquisa procura diagnosticar, portanto, um problema específico numa situação específica, com vistas a alcançar algum resultado prático. 0 pesquisador situa-se como observador participante ativo, pois desempenhará o papel de pesquisador e concomitantemente, de membro do grupo: "ele está simultaneamente dentro e fora do grupo" (Barbier, 2004, p.127).

Barbier (2004) reforça que as ciências humanas são, essencialmente, ciências de interações sujeito e objeto de pesquisa e acrescenta: "A pesquisa-ação é transpessoal quando reúne três polos integrados do ser humano: corpo, alma e espírito - imaginário pulsional, imaginário social e imaginário sacral" (p.41). Visto que o diferencial da presente pesquisa é realizar uma relação efetiva entre conhecimentos teóricos articulados a uma finalidade intencional, de alteração da situação pesquisada, a pesquisa-ação foi a que mais se encaixou para o alcance desta investigação.

Ressalta-se, portanto, que a pesquisa-ação estrutura-se na perspectiva de uma investigação preocupada com a participação consciente, criadora e construtiva do professor-pesquisador e os sujeitos envolvidos no campo. Trata-se ainda de uma metodologia investigatória ideal para uma pesquisa relacionada à prática em sala de aula, visto sua potencialidade de levar soluções imediatas para problemas educacionais urgentes. Como limitações, a metodologia aqui escolhida tem apresentado pouco ou nenhum controle sobre as variáveis, em consequência disso, os resultados não poderão ser generalizados, sendo válidos apenas no ambiente restrito em que as investigações foram realizadas.

Inicialmente foi realizado um levantamento bibliográfico sobre as teorias relacionadas a cartografia escolar no ensino de Geografia no Ensino Fundamental. Posteriormente um outro levantamento bibliográfico com o objetivo de compreender melhor a questão da alfabetização e letramento cartográfico no ensino de Geografia no Ensino Fundamental, bem como, quais são as concepções e tipos de atlas escolares geográficos municipais na Educação Básica existentes no país.

A pesquisa está sendo realizada na Rede Municipal de Educação de Conceição de Macabu, que atualmente possui duas escolas públicas com Ensino Fundamental (Anos Finais). Participaram da construção do Atlas Escolar Geográfico Municipal três professores de Geografia da Rede Municipal citada, atuantes nas turmas do sexto ao nono ano. Optou-se por esses sujeitos para a participação na pesquisa, por estarem diretamente ligados ao processo de ensino-aprendizagem nas aulas de Geografia com os alunos. 
Diferentes instrumentos de coletas de dados foram utilizados. Inicialmente um questionário exploratório online foi aplicado aos professores de Geografia que atuam nos anos finais do Ensino Fundamental na Rede Municipal de Educação de Conceição de Macabu, com o objetivo de situar o problema de pesquisa apresentado anteriormente e traçar caminhos para a pesquisa. De posse dos resultados do questionário exploratório inicial, foi possível verificar os anseios dos professores e as sugestões para o a confecção do protótipo do atlas.

Posteriormente, iniciou-se com o apoio dos três professores de Geografia a elaboração do protótipo do atlas escolar geográfico municipal através de levantamento de dados geográficos sobre o município de Conceição de Macabu. Os mapas temáticos que compõem o atlas foram produzidos pelo pesquisador com o apoio dos professores através do QGIS, software gratuito que possibilita a visualização, edição e análise de dados georreferenciados. Os dados utilizados para a produção dos mapas foram coletados do site do IBGE e Prefeitura do município.

Num quarto momento, com o objetivo de potencializar e dinamizar a produção coletiva do atlas, foi realizado uma oficina com a participação dos professores de Geografia, que puderam realizar observações e avaliações do material em construção. Buscou-se nesse momento avaliar as lacunas e sugestões dos professores para a melhoria do material didático. Após a realização da oficina sobre o protótipo do atlas com os professores de Geografia, foi aplicado um último questionário avaliativo do material aos professores participantes.

Por fim, de posse dos registros do diário de campo, questionário inicial exploratório, observações sobre a realização da oficina de avaliação do protótipo do atlas e questionário de avaliação do material didático aplicado aos professores de Geografia da Rede Municipal, está sendo possível realizar análises, interpretações e avaliações dos resultados com base no referencial teórico-metodológico relacionado a pesquisa-ação, cartografia escolar e as competências e habilidades relacionadas à alfabetização e letramento cartográfico no ensino de Geografia apresentadas nos documentos oficiais do Ensino Fundamental.

Ressalta-se que a pesquisa apresenta diversos benefícios para os alunos e comunidade escolar participante, visto que poderão construir novos conhecimentos relacionados à geografia local, contribuirá ainda para a formação de alunos pensantes e críticos, por meio do desenvolvimento de habilidades leitura e criação de representações do espaço em que vivem.

\section{Resultados e discussão}

A Base Comum Comum Curricular (BNCC) para o Ensino Fundamental elaborada recentemente pelo $\mathrm{MEC}$, apresenta uma unidade temática intitulada "Formas de representação e pensamento espacial" onde com relação a aprendizagem dos alunos, espera-se que:

[...] tenham domínio da leitura e elaboração de mapas e gráficos, iniciando-se na alfabetização cartográfica. Fotografias, mapas, esquemas, desenhos, imagens de satélites, audiovisuais, gráficos [...]. Quanto mais diversificado for o trabalho com linguagens, maior o repertório construído pelos alunos, ampliando a produção de sentidos na leitura de mundo. Compreender as particularidades de cada linguagem, em suas potencialidades e em suas limitações, conduz ao reconhecimento dos produtos dessas linguagens não como verdades, mas como possibilidades (Brasil, 2017, p. 315).

Ainda na BNCC do Ensino Fundamental, é esperado que nos anos finais, com relação a construção da linguagem cartográfica:

[...] os alunos consigam ler, comparar e elaborar diversos tipos de mapas temáticos, assim como as mais diferentes representações utilizadas como ferramentas da análise espacial. Essa, aliás, deve ser uma preocupação norteadora do trabalho com mapas em Geografia. Eles devem, sempre que possível, servir de suporte para o repertório que faz parte do raciocínio geográfico, fugindo do ensino do mapa pelo mapa, como fim em si mesmo (Brasil, 2017, p. 316)

Castellar (2011) situa claramente a cartografia escolar dentro de um universo mais amplo do que conceitua como letramento cartográfico, no sentido de desenvolver uma forma geográfica de pensar ou de analisar a realidade. As reflexões da autora encaminham-se para a perspectiva desta pesquisa, ao situar a cartografia escolar em um processo mais amplo de pensar com o uso do espaço, fugindo das afirmações frequentemente encontradas nos textos da área que, explícita ou implicitamente, advogam que o domínio dos códigos cartográficos, por eles mesmos, conduz o aluno a pensar geograficamente ou espacialmente. Nesse sentido a pesquisadora demonstra de maneira mais clara sua proximidade com a ótica desse trabalho quando compreende o letramento cartográfico como:

Ensinar a ler em Geografia significa criar condições para que a criança leia o espaço vivido, utilizando-se da cartografia como linguagem. Ensinar a ler o mundo possui uma dimensão espaço-temporal, na medida em que o aluno necessita estruturar as redes conceituais, por exemplo, quanto tem de reconhecer a localização do lugar, os símbolos utilizados e as distâncias entre os lugares, conseguindo identificar as paisagens e fenômenos cartografados e atribuindo sentido ao que está escrito (Castellar, 2011, p.123). 
Tal concepção da autora corrobora para uma compreensão de um letramento em Geografia que vai além das propostas que privilegiam apenas a apropriação de um alfabeto cartográfico, mas que compreendem um processo de produção de sentidos que envolve a participação dos sujeitos na construção e reconstrução de ideias e de sentidos com os autores e futuros leitores e construtores de mapas.

Neste contexto, os atlas geográficos escolares municipais se apresentam como um material didático a ser utilizado nas aulas de Geografia no Ensino Fundamental, e pode ser elaborado sob diferentes concepções de ensino que podem levar os alunos a uma melhor compreensão crítica e reflexiva acerca da realidade local. Através de levantamento bibliográfico, constatou-se que diferentes são as formas de uso e concepção da construção e uso de atlas escolares geográficos municipais. Com relação a esta reflexão, Martinelli (2008) ressalta que:

A concepção de um atlas geográfico para escolares tem como proposta básica, a de não ser apenas uma coletânea de mapas, prontos e acabados, mas sim, de compor uma organização sistemática de representações trabalhadas com finalidade intelectual específica. Para a sua coordenação, considera-se o entrelaçamento de duas orientações básicas: o "ensino do mapa", lastreado nas posturas teórico-metodológicas sobre a construção da noção de espaço e respectiva representação, pela criança e o "ensino pelo mapa", baseado na promoção do conhecimento do mundo através dos mapas, a partir do próximo, vivenciado e conhecido-o lugar-ao distante desconhecido-o espaço mundial. 0 conteúdo temático se fundamenta numa lucubração básica do conhecimento geográfico: a natureza em composição com a sociedade (p. 21).

Atualmente podem ser encontrados diversos tipos de atlas escolares geográficos no Brasil, com diferentes concepções teórico-metodológicas desses materiais didáticos nas escolas, sendo elas:

1. Atlas de referência nacional de concepção clássica: compostos por um conjunto de mapas "pronto" e "acabado", sem atividade do aluno e sem apresentação do material nem orientações metodológicas para o professor.

2. Cadernos de mapas: empregando diferentes linguagens (mapas, desenhos, fotos, maquetes, gráficos, imagens de satélite, textos explicativos, entre outras), centrados na atividade do aluno, com ou sem apresentação do material ou orientações para o professor.

3. Atlas escolares municipais: com informações organizadas e dados atuais sobre o município, temas sem uma sequência fixa, apresentação do material e de seus objetivos, com ou sem orientações metodológicas para os professores, alguns com e outros sem nenhuma participação de alunos e professores presentes na escola.
Le Sann (2001), pesquisador da área da cartografia escolar, ressalta que: "[...] atualmente, cada vez mais pesquisadores vêm demonstrando o potencial da cartografia como precioso instrumento facilitador da construção de noções básicas de Geografia, principalmente com a elaboração de atlas escolares locais e regionais [...]" (p. 131).

Compreende-se, portanto, que atlas escolares geográficos municipais, resultam de um esforço intencional dos que os constroem. Quem o elabora tem um objetivo pré-definido, o que the confere coerência, bem como o uso adequado de diferentes representações para análises e estudos do espaço geográfico. Por outro lado, o emprego dos atlas como recurso para aprendizagem apresenta distintos usos. Tais usos estão correlacionados ao currículo escolar, por extensão, aos PCNS e mais recentemente a BNCC, mas, principalmente aos objetivos específicos do professor correlacionados aos seus preceitos formativos e posicionamentos do docente.

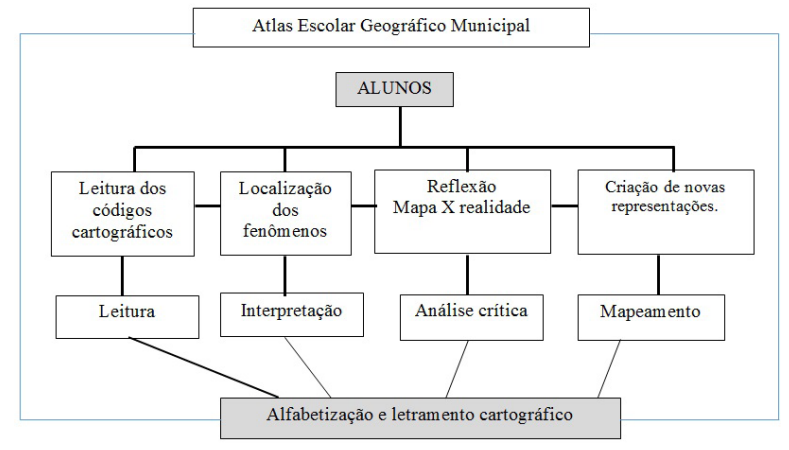

Figura 2. Esquema básico do Atlas.

Fonte: elaboração própria.

Visto que a pesquisa encontra-se em andamento, o resultado dos estudos realizados até o momento através de levantamento bibliográfico sobre o problema de pesquisa, leva a compreender que diferentes tipos de atlas escolares geográficos municipais foram elaborados no Brasil, porém, poucas reflexões metodológicas sobre o processo de planejamento, produção e avaliação do material didático na perspectiva da alfabetização e letramento cartográfico no Ensino Fundamental foram realizadas.

Foi possível analisar através da aplicação do questionário online inicial da pesquisa, que os professores de Geografia atuantes na Rede Municipal de Educação de Conceição de Macabu, em geral, possuem formação específica na área da Geografia, através de cursos de licenciatura plena. Os professores participantes possuem também formação continuada por meio de cursos de especialização lato sensu na área educacional e apenas um realizou posteriormente ao término da licenciatura em Geografia algum curso ligado diretamente à cartografia escolar no ensino de Geografia. 
Em geral, os professores de Geografia participantes costumam utilizar mapas temáticos em diferentes escalas durante as aulas da disciplina e possuem bastante dificuldade no acesso a mapas temáticos em escala local, referentes à geografia do município da pesquisa, no qual as escolas públicas estão localizadas.

A perspectiva do aluno leitor de mapas foi bastante presente ao longo das respostas dos questionários aplicados. Os professores ressaltaram a leitura e interpretação de mapas como habilidades de suma importância no processo de alfabetização e letramento cartográfico. Apenas um professor quando perguntado sobre como trabalha com mapas nas aulas, citou a habilidade de confecção de mapas como forma de trabalho com a cartografia escolar no ensino de Geografia no Ensino Fundamental. Todos os professores apontaram a importância da elaboração do Atlas Escolar Geográfico Municipal como material didático nas aulas de Geografia, visto que irá contribuir para a formação dos alunos.

Ressalta-se que a participação efetiva dos professores de Geografia colaboradores, vinculados a Rede Municipal de Educação de Conceição de Macabu, está possibilitarando e contribuindo de maneira satisfatória para a realização dessa pesquisa que propõe a produção de um atlas escolar geográfico municipal no contexto da escola pública, utilizando-se da metodologia da pesquisa-ação, bem como, a compreensão de que forma este material didático pode contribuir no processo de alfabetização e letramento cartográfico no ensino fundamental.

Por fim, espera-se que com a conclusão posterior desse trabalho, os professores de Geografia colaboradores possam construir novas cartografias de análises para a compreensão da espacialidade no município de Conceição de Macabu e sua relação com outras escalas, bem como, o aguçar de reflexões que movam para possíveis intervenções conscientes e críticas sobre a realidade espacial em práticas pedagógicas, que culminem na realização de outras novas pesquisas.

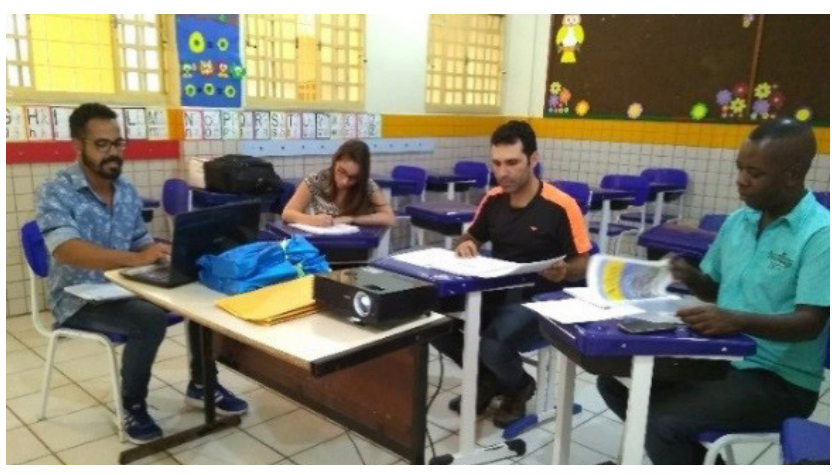

Figura 3. Oficina de elaboração do Atlas Escolar Geográfico Municipal de Conceição de Macabu/RJ com os professores de Geografia da Rede Municipal de Educação.

Fonte: elaboração própria.

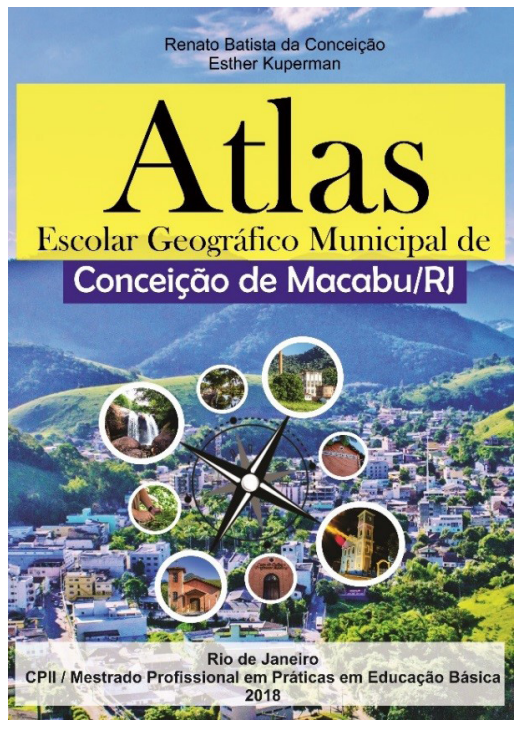

Figura 4. Capa do Atlas.

Fonte: elaboração própria.

\section{Considerações finais}

A opção pela metodologia da pesquisa-ação tem possibilitado a participação efetiva dos professores de Geografia vinculados a Rede Municipal de Educação de Conceição de Macabu no processo de elaboração do atlas escolar geográfico municipal. Ao longo de todo o percurso de elaboração do material didático (produção de textos, mapas e escolha de imagens), observa-se um cuidado com relação ao respeito a idade mental dos alunos, recorte espacial e também com a diversificação dos conteúdos de maneira apropriada para aproveitamento nos diferentes anos finais do Ensino Fundamental.

Considerando o ensino pelo mapa, almeja-se que o atlas em construção contribua com a alfabetização e letramento cartográfico dos alunos, fazendo-os capazes de realizarem leituras, análises, interpretações e construções de mapas. Com relação ao ensino do mapa, em todos os capítulos que compõem o atlas é possível encontrar atividades práticas nomeadas de "Desafios Geográficos", que possuem como objetivo principal o de fazer com que os alunos criem noções básicas de vizinhança, separação, ordem, inclusão e continuidade. Essas atividades visam contribuir para que os alunos sejam construtores de mapas simples, de modo a representar a sua realidade próxima utilizando elementos cartográficos. Além do trabalho com representações, as atividades de construção de gráficos simples, como o de coluna, visam possibilitar aos alunos a interpretação de fenômenos espaciais ao longo do tempo. 
O atlas em construção, de 70 páginas, reúne orientações gerais para o professor trabalhar o material em sala de aula. Posteriormente são apresentadas aos alunos breves apontamentos sobre a leitura, interpretação e confecção de mapas. 0 primeiro capítulo faz um breve histórico do município de Conceição de Macabu. O segundo trabalha o lugar de moradia do aluno e sua relação com o município. 0 terceiro a dinâmica socioambiental do município. O quarto capítulo a dinâmica demográfica e política do município. 0 quinto os aspectos da economia macabuense, e por fim, no sexto e último capítulo, atividades motivadoras de reflexão com relação ao futuro da cidade em que vivem.

Uma primeira ideia de complementação e de estudo futuro para a presente pesquisa será a aplicação do Atlas nas turmas dos Anos Finais do Ensino Fundamental no município de Conceição de Macabu, com o objetivo de tecer reflexões mais aprofundadas relativas aos resultados da aprendizagem dos alunos ao utilizarem o material didático nas aulas de Geografia.

Espera-se que com a conclusão posterior do trabalho, os professores de Geografia colaboradores possam construir novas cartografias de análises para a compreensão da espacialidade no município de Conceição de Macabu e sua relação com outras escalas, bem como, o aguçar de reflexões que movam para possíveis intervenções conscientes e críticas sobre a realidade espacial, com práticas pedagógicas criativas e inovadoras que possam culminar na realização de outras novas pesquisas relacionadas a cartografia escolar.

\section{Referências}

Barbier, R. (2004). A pesquisa-ação. Brasília: Líber Livro Editora.

Ministério da Educação. (2017). Base Nacional Comum Curricular. Brasília: MEC.

Castellar, S. (2011). Cartografia e a construção do conhecimento em contexto escolar. In R. Almeida (Ed.), Novos rumos da cartografia escolar: currículo, linguagem e tecnologia (pp. 121-135). São Paulo: Contexto.

Gil, A. (2010). Como elaborar projetos de pesquisa. São Paulo: Atlas.

Le Sann, J. (2001). Do lápis à internet: reflexões sobre mudanças teórico-metodológicas na elaboração da Atlas Escolares Municipais. Boletim de Geografia, 19(2), 130-138.

Martinelli, M. (2008). Um atlas geográfico escolar para o ensino-aprendizagem da realidade natural e social. Portal da Cartografia, 1(1), 21-34.

Thiollent, M. (2011). Metodologia da Pesquisa-Ação. São Paulo: Editora Cortez.

Tripp, D. (2005). Pesquisa-ação: uma introdução metodológica. Educação e Pesquisa, 31(3), 443-466. 